\title{
Examining Digital Government (DG) Adoption in Indonesia through UTAUT Framework
}

\author{
Deden Witarsyah Jacob ${ }^{1 *}$, Mohd Farhan Md Fudzee ${ }^{2}$, Mohamad Aizi Salamat ${ }^{2}$, Shahreen Kasim ${ }^{2}$ \\ ${ }^{1}$ Information System Department, Telkom University Jln Telekomunikasi no. 1 Bandung, Indonesia , \\ dedenw@telkomuniversity.ac.id \\ ${ }^{2}$ Faculty of Computer Science and Information Technology, Universiti Tun Hussein Onn Malaysia, \\ farhan@uthm.edu.my
}

\begin{abstract}
Public demand for better, accountable, fast and satisfactory services encourages the government to provide a reliable electronic service (digital-government) that can be accessed whenever and wherever. The issuance of Indonesian Presidential Instruction No. 3 of 2003 was an early milestone in the use of digital government services on a national scale. However, the challenges faced by the Indonesian government is to determine the key factors of the public satisfaction in adopting the digital-government. The goal of this paper is to explore the key factors that influences Indonesians' people in adopting the digital government based on the UTAUT framework. In this work, five hypotheses are formulated and five factors are identified that may affect the Indonesians' level of adoption towards using the digital services. Survey data from 237 citizens in five big cities in Java and Sumatra region of Indonesia were collected and used to test the proposed hypotheses. Based on the structural equation model (SEM) approach, the results present several key findings that are in line with the goal of the government to create digital-government that are compatible with citizens' needs, desires, and expectations these findings indicated, thus unveiling the key drivers of adoption level. The result of the work also presents deep insight for governmental policy-makers and practitioners to increase digital-government service via behavioral and managerial factors. Finally, implications and recommendations of these findings were discussed.
\end{abstract}

Key words : Digital government, Indonesia, Adoption, UTAUT Framework, SEM.

\section{INTRODUCTION}

The development of Information and Communication Technology (ICT) now has a big impact for the world. Indeed, it makes several changes in behavior of human life and government, include the public sector services. West simply defines digital-government as follows: Activities are undertaken by governments using Information Technology (IT) to provide services to the public [23]. Meanwhile World Bank states digital-government refers to the use of government agencies of information technologies such as the Internet, and smartphone that can transform relations with citizens, businesses, and other arms of government [25].
These technologies can serve a variety of different ends: better delivery of government services to citizens, improve interactions with business and industry, citizen empowerment through access to information. Rigid government services today can be overcome with digital-government to become more flexible, and more oriented to user satisfaction [24].

Some researchers argue that one of the most important factors for successful digital-government services is the acceptance and willingness of people to adopt digital-government services [1]-[3].Based on the report of the 13th Waseda University in International Digital Government ranking 2017, Indonesia ranks $32^{\text {th }}$ out of 65 countries in the world as a country that adopts a digital-government system in running a government system [4]. Indonesia still stays behind ASEAN member countries such as Thailand [21], but quite superior to Philippines [33] and Malaysia [36]. Whereas the opportunity for development of digital-government usage in Indonesia is very big considering the number of internet users in 2017 reached 121.6 million.

The level of public participation in adopting digital-government is certainly influenced by certain factors. These factors need to be known to be an input to the government in increasing the participation of its people in adopting digital-government services so that digital-government provided by the government is not a waste. Therefore, the assessment of the factors that affect the acceptance and use of digital-government is an important thing.

This study tries to explore factors that affect the acceptance of digital-government in Indonesia using the Unified Theory of Acceptance and Use of Technology (UTAUT) model [10]-[16]. Furthermore, Structural Equation Modeling (SEM) was chosen to determine the relationship between variables in the model. Furthermore, research question for this work is "What factors affect the usage of digital-government services in Indonesia based on the UTAUT framework?"

\section{RELATED WORKS}

\subsection{Transformation from Electronic-Government (EG) to Digital-Government (DG}

The Digital Government landscape is continuously changing to reflect how governments are trying to find innovative 
digital solutions to social, economic, political and other pressures, and how they transform themselves in the process [4]. According to Waseda University the transformation from [electronic-government] to [Digital government] as the new definition which covers more comprehensive activities [26]. Both Digital Innovation and Digital Economy are the keys for economic growth and challenges. five highlights of the new trends in digital-government such as Mobile Government, Artificial Intelegent and Internet of Think for Digital Government, Smart City, Cloud Computing Technology and Digital Government, and ICT for Anti-Corruption.

\subsection{The acceptance of Information Technology}

Studies on technology adoption have aimed to understand, predict and explain variables influencing adoption behavior at the individual as well as organizational levels to accept and use technological innovations [26]. There are still some inhibiting factors that are very influential people in using information technology, so its utilization is still very less. Furthermore, if technical obstacles can be overcome, it becomes a very important factor in developing the ability to create applications for users. Meanwhile, The Unified Theory of Acceptance and Use of Technology (UTAUT) is one of the most recent models of technological acceptance developed by Venkatesh et al [10]. UTAUT synthesizes elements in eight leading technology acceptance models to gain a unified view of user acceptance.

\subsection{Structural Equation Modeling}

Structural Equation Modeling (SEM) is a statistical model used to describe relationships between several variables [6]. SEM examines the interdependent structure among the variables described in several equations. These equations describe the overall relation between constructs (dependent variables and independent variables).

\section{EXPERIMENTAL PROCEDURES}

\subsection{Research Framework}

This study is an empirical study to test hypotheses on the following research problems. The research framework is shown in Fig. 1. The work was started with developing a research model, and the designing a questionnaire, furthermore the questionnaire have to check the reliability before distributed. The Final stage is SEM PLS analysis to know the hypotheses includes the relationship between major dependent variables and independent variables.

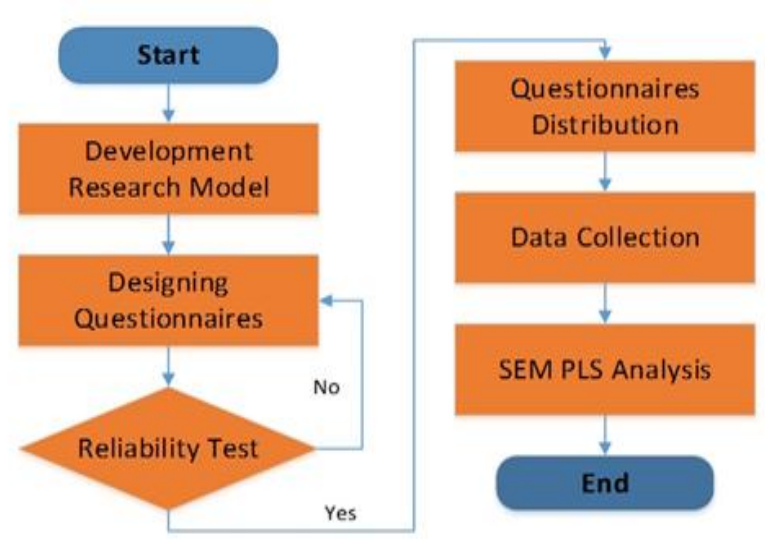

Figure 1: Research Framework

\subsection{Research Method}

This research adapted UTAUT framework for measuring the level of digital-government adoption [5-9]. Unlike some other models, UTAUT is quite popular because it is able to account for nearly 70 percent of behavioral intentions to empower a system or technology [10]. Furthermore, Digital-government has been regarded as a reliable support technology because of its excellent ability to exchange information between government and citizens.

The rationale behind deploying the UTAUT framework is support in examining the social and other factors which impact the information technology linked with technology adoption. UTAUT is one of the latest technology acceptance models developed by Venkatesh, et al. UTAUT combines the successful features of eight leading technology acceptance theories into one theory (Figure 2).

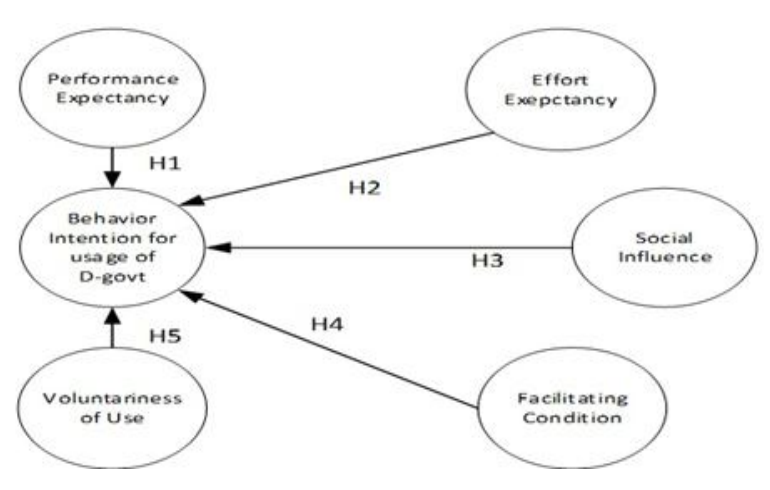

Figure 2: Research Method

\subsubsection{Performance Expectancy (PE)}

Performance expectancy (PE) is the most powerful variable affecting a person's intention to use information systems [10]-[16]. Furthermore, PE variable has a positive relationship with behavior invention in accordance with previous studies [11]-[13]. This positive relationship 
illustrates that the higher the level of confidence a person in using digital-government will be able to improve their performance, the higher the intention of the person to use digital-government. Therefore, the first hypothesis (H1) is PE is positively linked with the behavioral intention to use and accept digital-government.

\subsubsection{Effort expectancy}

Effort expectancy (EE) informs that the person feels the digital-government system is not difficult to use and also does not require a high skill effort to use it so that the higher the intention of the person to use the system when available later. This relationship in line with past work which says that effort expectancy is positively associated with behavior intention [14]-[17]. Hence, the second hypothesis (H2) is derived as: Effort expectancy gives a positive influence on the improvement of one's intention-behavior in using the digital-government system.

\subsubsection{Social influence}

Social influence can be interpreted as an attempt made by an individual or more in changing a belief, perception and behavior of others [16]. Therefore, the influence of colleagues, friends, and family members can be decisive for individuals in using the digital government, so the hypothesis (H3) states that the SI is positively related to behavioral intent to use and accept the digital government.

\subsubsection{Facilitating condition}

Facilitating conditions (FC) can be defined as the extent to which one believes that organizational and technical infrastructures are available to support the operation of the system [10,16]. Next, hypothesis (H4) for FC is positively linked with the behavioral intention to use digital-government.

\subsubsection{Voluntariness of Use}

The Voluntariness of Use (VU) describes the level of individual trust in using or accepting technology, so far the digital-government is perceived as a technology that can be used voluntarily and there will be a greater trend in the future in its use. [10]. Therefore, the hypothesis (H5) is: VU is positively related to behavioral intent to use and receive digital government.

\section{EXPERIMENTAL RESULT}

\subsection{Demographic Data}

Data used in this study is the result of the survey conducted in 2016. The population of data used in this study based on the survey in several major cities in Indonesia. The survey method was conducted through an online survey.

Table 1: Characteristics of respondents

\begin{tabular}{|c|c|c|c|}
\hline \multirow{2}{*}{ Demographic } & Category & \multicolumn{2}{|c|}{ Sample } \\
\cline { 3 - 4 } & & $\mathrm{N}$ & Percent \\
\hline \multirow{3}{*}{ Gender } & Male & 97 & $40.9 \%$ \\
\cline { 2 - 4 } & Female & 140 & $59.1 \%$ \\
\hline \multirow{3}{*}{ Age } & Under 30 & 230 & $96.9 \%$ \\
\cline { 2 - 4 } & $31-40$ & 4 & $1.6 \%$ \\
\cline { 2 - 4 } & $41-50$ & 3 & $1.2 \%$ \\
\cline { 2 - 4 } & Above 50 & - & \\
\hline DG User & Less than 1 year & 2 & $0.8 \%$ \\
\cline { 2 - 4 } Experience & 1-3 Years & 127 & $53.5 \%$ \\
\cline { 2 - 4 } & 4-6 Years & 102 & $45.7 \%$ \\
\hline
\end{tabular}

Table 1 shows a description of data population. Demographic data shows that most digital-government users are women with a long experience of about one to three years. Although this technology is more than a year old, this illustrates that some new respondents in using this technology. This may reflect the lack of user enthusiasm in using the system.

\subsection{Partial Least Squares (Pls) Approach}

\subsubsection{Descriptive statistics, validity and reliability tests}

Smart PLS 3.0 statistical software for the data analysis, including factor analysis and hypothesis testing, was chosen to make a modeling based on structural equation modeling approach. One of the characteristics of PLS is robust against multicollinearity and can make no assumptions about the distribution of the variables $[18,19]$. Although, the research model is relatively small with large numbers of indicators, small sample sizes, and moderators the PLS can analyze the data very well [6].

Furthermore, based on the finding result, each construct has achieved convergent validity with factor loading value more than 0.7 except for two item in EE2 and FC2, which was deleted. The value of loading factor ranging from 0.703 to 0.919. Next, the value of Convergent and discriminant validity also have passed the minimum limit where AVE $>0.5$, ranging from 0.576 to 0.827 , and with acceptable cross-loadings results. Table 2 and 3 represents the highest values for each item, which are correctly loaded on variables to be measured. This further indicates good discriminant validity. Reliability was also achieved (CR $>0.7$; Cronbach $\alpha>$ $0.7)$.

Table 2: Structural model fit indices

\begin{tabular}{|l|l|}
\hline Dependent Variables & $\mathrm{R}^{2}$ \\
\hline Behavior Intention & 0.70 \\
\hline
\end{tabular}


Table 3: PLS Analysis Result

\begin{tabular}{|l|l|l|l|l|}
\hline $\begin{array}{l}\text { Hypo } \\
\text { thesis }\end{array}$ & $\begin{array}{l}\text { Relationsh } \\
\text { ips of } \\
\text { variables }\end{array}$ & $\begin{array}{l}\text { Path } \\
\text { Coefficient } \\
\mathrm{s}\end{array}$ & $\begin{array}{l}t \text { - } \\
\text { statistic }\end{array}$ & Result \\
\hline H1 & PE $\rightarrow$ BI & 0,214 & 3,354 & $\begin{array}{l}\text { Suppor } \\
\mathrm{t}\end{array}$ \\
\hline H2 & EE $\rightarrow$ BI & $-0,120$ & 2,034 & $\begin{array}{l}\text { Suppor } \\
\mathrm{t}\end{array}$ \\
\hline H3 & SI $\rightarrow$ BI & 0,074 & 1,453 & Not \\
\hline H4 & FC $\rightarrow$ BI & 0,421 & 6,082 & $\begin{array}{l}\text { Suppor } \\
\mathrm{t}\end{array}$ \\
\hline H5 & VU $\rightarrow$ BI & 0,357 & 4,556 & $\begin{array}{l}\text { Suppor } \\
\mathrm{t}\end{array}$ \\
\hline
\end{tabular}

\subsubsection{Structural model analysis}

The significance values of the path coefficients have to achieve more 1.96 or in other word t-value $>1.96$. The result of the model show t-value ranging from 1,453 to 6,082 , it means that one of the five hypotheses were not supported. Meanwhile, based on the running analysis model has achieved fit value where R2 > 0.1. Correlation between FC to BI was found as the most significant relationship, followed by $\mathrm{VU}$, PE, and the last EE. However, the results also showed that SI does not moderate the relationship.

This study using structural equation modeling (SEM) technique, hence obtained $t$ value or coefficient of the relation between latent variables. By looking at these values, the proposed research hypotheses can be evaluated.

Hypothesis 1: H0: $\rho=0 \rightarrow$ PE does not positively affect the $\mathrm{BI}$ community in using digital-government. H1: $\rho \neq 0 \rightarrow \mathrm{PE}$ positively affects the BI community in using digital-government. From the data processing, it is known that the value of $\mathrm{t}$ for the relationship of PE and $\mathrm{BI}$ is 3,354 which exceeds the value of 1,96 (at $\alpha=5 \%$ ), that means, $\mathrm{H} 0$ is rejected and $\mathrm{H} 1$ is accepted so it can be concluded that PE can positively influence to BI society in using digital-government. This result is consistent with previous studies which suggest that intention is a critical determinant of use [14[20],[21]. If digital-government can help and improve the performance of community performance it will increase their motivation to use the system.

Hypothesis 2: H0: $\rho=0 \rightarrow$ Effort expectancy does not give positive effect to the increase of behavioral intention of society in using digital-government. H1: $\rho \neq 0 \rightarrow$ Effort expectancy gives positive influence on the increase of behavioral intention of society in using digital-government. From the result of data processing found that $t$ value for effort expectancy and behavioral intention relation 2,034 more than value 1,96 (at $\alpha=5 \%$ ), then $\mathrm{H} 0$ refused and $\mathrm{H} 1$ accepted so it can be concluded that effort expectancy gives positive influence to behavioral intention society in using digital-government. This result is in accordance with previous studies which suggest that effort expectancy significantly positively affects behavioral intention [10], [14], [20], [21].
The information above describes that the current ability of a person in using a computer is getting better where the level of ease in using a computer-based system is not disputed [22].

Hypothesis 3: H0: $\rho=0 \rightarrow$ Social influence does not give a positive influence in the increase of behavioral intention of society in using digital-government. H1: $\rho \neq 0 \rightarrow$ Social influence gives a positive influence in increasing behavioral intention of society in using digital-government. From the result of data processing found that $t$ value for social influence relationship and behavioral intention equal to 1,453 where a value less than 1,96 (at $\alpha=5 \%$ ), then $\mathrm{H} 0$ accepted and $\mathrm{H} 1$ rejected so it can be concluded that SI has no positive effect on behavioral intention society in using digital-government. This result is not in accordance with previous research which states that Social influence gives positivity effect to behavioral intention [10],[16].

Hypothesis 4: H0: $\rho=0 \rightarrow$ Facilitating condition does not give positive influence to BI society in using digital-government. H1: $\rho \neq 0 \rightarrow$ Facilitating condition gives positive influence to BI society in using digital-government. From the result of data processing found that $\mathrm{t}$ value for the relation of $\mathrm{FC}$ and $\mathrm{BI}$ equal to 6,082, the value more than 1,96 (at $\alpha=5 \%$ ), it means that $\mathrm{H} 0$ rejected and $\mathrm{H} 1$ accepted, so it can be concluded that Facilitating condition give positive influence to BI society in using digital-government. This result is in accordance with previous research which states that facilitating condition has a positive effect on BI [10], [22].

Hypothesis 4: H0: $\rho=0 \rightarrow$ Facilitating condition does not give positive influence to BI society in using digital-government. H1: $\rho \neq 0 \rightarrow$ Facilitating condition gives positive influence to BI society in using digital-government. From the result of data processing found that $\mathrm{t}$ value for the relation of $\mathrm{FC}$ and $\mathrm{BI}$ equal to 6,082, the value more than 1,96 (at $\alpha=5 \%$ ), it means that $\mathrm{H} 0$ rejected and $\mathrm{H} 1$ accepted, so it can be concluded that Facilitating condition give positive influence to BI society in using digital-government. This result is in accordance with previous research which states that facilitating condition has a positive effect on BI [10]-[22].

Hypothesis 5: H0: $\rho=0 \rightarrow \mathrm{VU}$ does not positively affect the BI community in using digital-government. H1: $\rho \neq 0 \rightarrow \mathrm{VU}$ gives positive influence to $\mathrm{VU}$ society in using digital-government. From the result of data processing found that value $\mathrm{t}$ for the relationship of $\mathrm{VU}$ and digital-government equal to 4,556 which exceed value 1,96 (at $\alpha=5 \%$ ), it means that $\mathrm{H} 0$ rejected and $\mathrm{H} 1$ accepted so it can be concluded that $\mathrm{VU}$ gives positive influence to $\mathrm{BI}$. This result is in accordance with previous studies [10]-[16].

\section{CONCLUSION}

There are several factors that affect the acceptance of digital-government either directly or indirectly. First influential factors are FC, this proves that supporting organizational and technological infrastructure has a direct 
bearing on the individual's propensity to use and accept a system or a technology. Furthermore, Second factor is VU, it proves that every individual believes that the usage and acceptance of digital-government technology voluntarily or freely without any obligation, will result in a greater tendency to accept and use existing digital-government technologies. Furthermore, third factor is performance expectancy, PE directly influences people's behavior to use digital-government. By using digital-government the expected service is faster and efficient. The last factor is EE, Finally, it can be concluded that this research has succeeded to build a potential model and play a role in digital-government acceptance.

\section{ACKNOWLEDGEMENT}

This work is supported by Universiti Tun Hussein Onn Malaysia by Grant vote no. U559, Telkom University and Gates Sdn Bhd publication grant.

\section{REFERENCES}

1. M.-C. Roy, A. Chartier, J. Crete, and D. Poulin, 'Factors influencing electronic-government use in non-urban areas," Electron. Commer. Res., vol. 15, no. 3, pp. 349-363, 2015. https://doi.org/10.1007/s10660-015-9193-4

2. V. Weerakkody, R. El-Haddadeh, F. Al-Sobhi, M. A. Shareef, and Y. K. Dwivedi, "Examining the influence of intermediaries in facilitating electronic-government adoption: An empirical investigation," Int. J. Inf. Manage., vol. 33, no. 5, pp. 716-725, 2013.

https://doi.org/10.1016/j.ijinfomgt.2013.05.001

3. N. P. Rana, Y. K. Dwivedi, and M. D. Williams, "A meta-analysis of existing research on citizen adoption of electronic-government," Inf. Syst. Front., vol. 17, no. 3, pp. 547-563, 2015. https://doi.org/10.1007/s10796-013-9431-z

4. T. Obi, The 12th Waseda - IAC International digital-government Rankings Survey 2016 Report, no. July. 2016.

5. Al. A. A. AL Athmay, K. Fantazy, and V. Kumar, "e-government adoption and user's satisfaction: an empirical investigation," EuroMed J. Bus. J. Bus., vol. 11, no. 1, pp. 57-83, 2016. https://doi.org/10.1108/EMJB-05-2014-0016

6. J. J. F. Hair, W. C. Black, B. J. Babin, and R. E. Anderson, "Multivariate Data Analysis (7Th, 2009).Pdf." p. 761, 2009.

7. M. S. Awwad and S. M. Al-Majali, "Digital library services acceptance and use: an empirical validation of unified theory of acceptance and use of technology," Electron. Libr., vol. 33, no. 6, pp. 1100-1120, 2015. https://doi.org/10.1108/EL-03-2014-0057

8. I. Abunadi and F. Alqahtani, "Instrument development and contextualization for perceived characteristics of e-transactions," Program-Digital Libr. Inf. Syst., vol. 51, no. 1, pp. 52-64, 2017.

https://doi.org/10.1108/PROG-04-2016-0035

9. M. Yuvaraj, "Adoption of technology in recruitment of library professionals and faculty members," Bottom Line, vol. 29, no. 4, pp. 241-250, 2016.

https://doi.org/10.1108/BL-03-2016-0016

10. V. Venkatesh, M. G. Morris, G. B. Davis, and F. D. Davis, "User Acceptance of Information Technology: Toward a Unified View," Source MIS Q., vol. 27, no. 3, pp. 425-478, 2003. https://doi.org/10.2307/30036540

11. M. Silic and A. Back, "Factors driving unified communications and collaboration adoption and use in organizations," Meas. Bus. Excell., vol. 20, no. 1, pp. 21-40, 2016. https://doi.org/10.1108/MBE-05-2015-0026

12. $\mathrm{H}$. $\mathrm{Xu}$, "Factors affecting faculty use of learning object repositories.," Electron. Libr., vol. 33, no. 6, pp. 1065-1078, 2015. https://doi.org/10.1108/EL-07-2014-0108

13. A. Tarhini, M. El-Masri, M. Ali, and A. Serrano, "Extending the UTAUT model to understand the customers' acceptance and use of internet banking in Lebanon," Inf. Technol. People, vol. 29, no. 4, pp. 830-849, 2016. https://doi.org/10.1108/ITP-02-2014-0034

14. D. W. Jacob, M. F. Fudzee, and M. A. Salamat, "A Conceptual Study on Generic End Users Adoption of electronic-government Services,” Int. J. Adv. Sci. Eng. Inf. Technol., vol. 7, no. 3, pp. 1000-1006, 2017. https://doi.org/10.18517/ijaseit.7.3.1654

15. O. Mosweu, K. Bwalya, and A. Mutshewa, Examining factors affecting the adoption and usage of document workflow management system (DWMS) using the UTAUT model, vol. 26, no. 1. 2016. https://doi.org/10.1108/RMJ-03-2015-0012

16. M. Williams, N. Rana, and Y. Dwivedi, The unified theory of acceptance and use of technology (UTAUT): a literature review, vol. 28, no. 3. 2015. https://doi.org/10.1108/JEIM-09-2014-0088

17. F. J. Rondan-Cataluña, J. Arenas-Gaitán, and P. E. Ramírez-Correa, "A comparison of the different versions of popular technology acceptance models," Kybernetes, vol. 44, no. 5, pp. 788-805, 2015. https://doi.org/10.1108/K-09-2014-0184

18. O. Al-Hujran, M. M. Al-Debei, A. Chatfield, and M. Migdadi, "The imperative of influencing citizen attitude toward electronic-government adoption and use," Comput. Human Behav., vol. 53, pp. 189-203, 2015. https://doi.org/10.1016/j.chb.2015.06.025

19. M. Fagan, C. Kilmon, and V. Pandey, "Exploring the adoption of a virtual reality simulation: The role of perceived ease of use, perceived usefulness and personal innovativeness," Campus-Wide Inf. Syst., vol. 29, no. 2, pp. 117-127, 2012. https://doi.org/10.1108/10650741211212368

20. D. W. Jacob, M. F. Md Fudzee, M. A. Salamat, S. Kasim, H. Mahdin, and A. A. Ramli, "Modelling End-User of 
electronic-Government Service: The Role of Information quality, System Quality and Trust," IOP Conf. Ser. Mater. Sci. Eng., vol. 226, p. 12096, Aug. 2017.

https://doi.org/10.1088/1757-899X/226/1/012096

21. D. W. Jacob, "The Critical Factors Affecting e-government Adoption in Indonesia: A Conceptual Framework," Int. J. Adv. Sci. Eng. Inf. Technol., vol. 7, no. 1, pp. 160-167, 2017. https://doi.org/10.18517/ijaseit.7.1.1614

22. V. Weerakkody, Z. Irani, H. Lee, I. Osman, and N. Hindi, "electronic-government implementation: A bird's eye view of issues relating to costs, opportunities, benefits and risks," Inf. Syst. Front., vol. 17, no. 4, pp. 889-915, 2015.

https://doi.org/10.1007/s10796-013-9472-3

23. West (2004). Electronic-government and the transformation of service delivery and citizen attitudes. Public Administration Review, 64(1), 15-27. https://doi.org/10.1111/j.1540-6210.2004.00343.x

24. [24] Rudiantara. (2014). Pembangunan Infrastruktur Telekomunikasi Tantangan), Dialog Akhir Tahun 2014 Masyarakat Telekomunikasi (Mastel). Jakarta: Kementerian Komunikasi dan Informatika.

25. World Bank, Electronic-government for all - Review of International Experience with Enhancing public Access, Demand and Participation in egovernment services: Toward a Digital Inclusion Strategy for Kazakhstan, ISG government Practice Technical Advisory Note 2006.

26. Gangwar, H. Date, and A. D. Raoot, "Review on IT adoption: insights from recent technologies," J. Enterp. Inf. Manag., vol. 27, no. 4, pp. 488-502, 2014. https://doi.org/10.1108/JEIM-08-2012-0047 